\title{
Múltiplas facetas do envelhecimento da população brasileira
}

\author{
Ana Paula Guarnieri \\ ${ }^{1}$ Curso de Enfermagem, Faculdade de Medicina do ABC (FMABC) - Santo André (SP), Brasil. E-mail: azuldomar2@ gmail.com
}

DOI: http://dx.doi.org/10.7322/abcshs.v41i3.900

A presente edição da $A B C S$ Health Sciences traz dois artigos relacionados às questões do envelhecimento populacional brasileiro, no tocante à qualidade de vida ${ }^{1}$ e à sexualidade ${ }^{2}$. Temáticas essas de suma importância, pois as projeções demonstram que o número de idosos até 2025 será superior a 30 milhões, e a velhice tanto poderá ser acompanhado por altos níveis de doenças crônico-infecto-contagiosas quanto por saúde e bem-estar ${ }^{3}$. A literatura científica evidencia que a grande maioria dos idosos apresenta nível elevado de comprometimento funcional, dependência e solidão ${ }^{4}$. Entretanto, envelhecer não é sinônimo de doença, inatividade e contração geral no desenvolvimento. Na literatura gerontológica, envelhecer é considerado um evento progressivo e multifatorial, e a velhice é uma experiência potencialmente bem-sucedida, porém heterogênea e vivenciada com maior ou menor qualidade de vida. $\mathrm{O}$ conceito de qualidade de vida relaciona-se à autoestima e ao bem-estar pessoal e abrange uma grande gama de aspectos, tais como: capacidade funcional; nível socioeconômico; estado emocional; interação social; atividade intelectual; autocuidado; suporte familiar; estado de saúde; valores culturais, éticos e religiosidade; estilo de vida; satisfação com as atividades da vida diária e com o ambiente em que se vive ${ }^{5}$. Fatores fundamentais numa avaliação gerontológica ampla. Tendo essa diversidade de fatores, o conceito de qualidade de vida é subjetivo e dependente do nível sociocultural, da idade, das aspirações pessoais de cada indivíduo, das crenças e dos valores ${ }^{6}$. Qualidade de vida pode ainda ser relacionada com as necessidades humanas básicas descritas na teoria de Maslow. A hierarquia das necessidades de Maslow baseia-se na ideia de que cada ser humano se esforça muito para satisfazer suas necessidades pessoais. Nessa divisão hierárquica, os imperativos considerados de nível mais baixo devem ser satisfeitos antes das necessidades de nível mais alto. Segundo essa teoria, cada indivíduo tem de realizar uma "escalada" hierárquica de necessidades para atingir a sua plena autorrealização e qualidade de vida. A sexualidade encontra-se entre as necessidades fisiológicas básicas, porém a expressão dessa função não previdente traz consequências importantes, como as Doenças Sexualmente Transmissíveis (DSTs), em especial a AIDS ${ }^{7}$. A velhice e a sexualidade são tabus que muitas vezes levam ao baixo empoderamento dessa população e às condições de riscos. Riscos esses demonstrados em dados epidemiológicos e também no estudo que se segue nesta edição. O baixo conhecimento ou, ainda, a influência de crenças e valores irreais podem por vezes determinar o curso da história de um grande número de idosos ativos sexualmente. As DSTs representam realidade para todas as idades, portanto se faz de suma importância o estudo nessa temática. Os dois estudos apresentados trazem importantes reflexões para a gerontologia das necessidades existentes ao desvelarmos o envelhecimento brasileiro em suas múltiplas facetas e necessidades.

\section{REFERÊNCIAS}

1. Lima BM, Araújo FA, Scattolin FAA. Qualidade de vida e independência funcional de idosos frequentadores do clube do idoso do município de Sorocaba. ABCS Health Sci. 2016;41(3):146-9.

http://dx.doi.org/10.7322/abcshs.v41i3.907

2. Brito NMI, Andrade SSC, Silva FMC, Fernandes MRCC, Brito KKG, Oliveira SHS. Idosos, infecções sexualmente transmissíveis e aids: conhecimentos e percepção de risco. ABCS Health Sci. 2016;41(3):140-5.

http://dx.doi.org/10.7322/abcshs.v41i3.902

3. Campolina AG, Adami F, Santos JLF, Lebrão ML. Effect of the elimination of chronic diseases on disability-free life expectancy among elderly individuals in Sao Paulo, Brazil, 2010. Ciênc Saúde Coletiva. 2014;19(8):3327-34

http://dx.doi.org/10.1590/1413-81232014198.06952013
4. Barreto MS, Carreira L, Marcon SS. Envelhecimento populacional e doenças crônicas: reflexões sobre os desafios para o Sistema de Saúde Pública. Rev Kairós Gerontol. 2015;18(1):325-39.

5. Teixeira, MCP, Carvalho FM, Lins L. Health-related quality of life of former lead workers in brazil. Int J Environ Res Public Health. 2015;12(11):14084-93.

http://dx.doi.org/10.3390/ijerph121114084

6. Varela FRA, Ciconelli RM, Campolina AG, Soarez PC. Quality of life evaluation of frail elderly in Campinas, São Paulo. Rev Assoc Med Bras. 2015;61(5):423-30.

http://dx.doi.org/10.1590/1806-9282.61.05.423

7. Maschio MBM, Balbino AP, Souza PFR, Kalinke LP. Sexualidade na terceira idade: medidas de prevenção para doenças sexualmente transmissíveis e AIDS. Rev Gaúcha Enferm. 2011;32(3):583-9. http://dx.doi.org/10.1590/S1983-14472011000300021 